\title{
Excesso de ferro sobre o desenvolvimento de porta-enxertos cítricos
}

\section{Kassio Ewerton Santos SOMBRA ${ }^{1 *}$, Andreza Cristina Chagas de OLIVEIRA ${ }^{2}$, Ronyce do Nascimento FERREIRA ${ }^{2}$, Alexandre Caique Costa e SILVA², Cleilson do Nascimento UCHÔA², Francisco Sildemberny Souza dos SANTOS ${ }^{3}$}

\begin{abstract}
${ }^{1}$ Programa de Pós-Graduação em Agronomia (Fitotecnia/Fitossanidade), Universidade Federal do Ceará, Fortaleza, CE, Brasil. ${ }^{2}$ Instituto Federal de Educação, Ciência e Tecnologia do Ceará, Campus Limoeiro do Norte, Limoeiro de Norte, CE, Brasil. ${ }^{3}$ Instituto Federal de Educação, Ciência e Tecnologia do Ceará, Campus Tabuleiro do Norte, Tabuleiro de Norte, CE, Brasil. *E-mail: kassiosombra@gmail.com
\end{abstract}

Recebido em janeiro/2018; Aceito em outubro/2018.

RESUMO: O trabalho objetivou avaliar os efeitos do excesso de ferro sobre a emergência e desenvolvimento inicial de genótipos de porta-enxertos cítricos. Adotou-se delineamento em blocos casualizados (DBC), em fatorial $5 \times 2$, com cinco porta-enxertos e dois substratos, repetidos quatro vezes, com parcela útil de 15 recipientes. Os genótipos consistiram do limoeiro ‘Cravo Santa Cruz'; citrandarins 'Riverside', 'San Diego' e 'Índio', além de, tangerineira 'Sunki Tropical', cultivados com ou sem óxido de ferro no substrato. Analisaramse as porcentagens de emergência (PE) e calculou-se o índice de velocidade de emergência (IVE). Realizaramse biometrias aos 30, 60 e 90 dias após a semeadura (DAS), mensurando-se a altura (H) e diâmetro de caule (D) das plântulas, determinando-se massa fresca (MV) e seca (MS). O excesso de ferro induziu subdesenvolvimento, e até mortalidade de plântulas já emergidas, o que refletiu diretamente nos resultados, porém, todos os genótipos apresentaram emergência superior a 75\%, destacando-se o citrandarin 'San Diego', com maior altura e caule mais espesso, e o citrandarin 'Riverside' com maior sensibilidade ao estresse, registrando os menores valores. $\mathrm{O}$ citrandarin 'San Diego' demonstrou tolerância o estresse e desenvolveu-se satisfatoriamente, necessitando estudos que avaliem a manutenção das características inferidas em combinação com a cultivar copa.

Palavras-chave: ambiente protegido, citricultura, enxertia, estresse, mudas.

\section{Excess of iron on the development of citrus rootstocks}

\begin{abstract}
The objective of this work was evaluated the effects of iron excess on the emergence and initial development of citrus rootstock genotypes. A randomized complete block design (DBC), factorial 5x2, with five rootstocks and two substrates, repeated four times, with useful plot of 15 containers was adopted. Genotypes consisted of the 'Santa Cruz' Rangpur lemon; 'Riverside', 'San Diego' and 'Indio' citrandarins, as well as 'Sunki Tropical' tangerine, grown with or without iron excess in substrate. The percentages of emergency (PE) were analyzed and the rate of emergency (IVE) was calculated. Biometry was performed at 30, 60 and 90 days after sowing (DAS), by measuring the height $(\mathrm{H})$ and stem diameter (D) of the seedlings, determining fresh (MV) and dry mass (DM). The excess of iron induced underdevelopment, and even mortality of already emerged seedlings, which reflected directly in the results, however, all genotypes presented an emergency higher to 75\%, standing out 'San Diego' citrandarin, with greater height and more stem thick, and the 'Riverside' citrandarin with greater sensitivity to stress, registering the lowest values. 'San Diego' citrandarin demonstrated stress tolerance and developed satisfactorily, requiring studies that evaluate maintenance of inferred characteristics in combination with cultivar canopy.
\end{abstract}

Keywords: protected environment, citriculture, grafting, stress, seedlings.

\section{INTRODUÇÃO}

A citricultura consolidou-se como uma importante cadeia produtiva do Brasil, contribuindo significativamente na geração de emprego e renda em todos os estados, e participando do desenvolvimento de pequenas e médias propriedades na região Nordeste, segunda maior produtora de citros do país (ALMEIDA; PASSOS, 2011).

A baixa diversificação de cultivares combinada com a alta susceptibilidade das plantas cítricas a pragas e doenças, são consideradas as principais vulnerabilidades na citricultura mundial, que tem como pilar o uso de mudas propagadas vegetativamente (enxertia e micro enxertia) (SOARES FILHO et al., 1997; CUNHA SOBRINHO et al., 2013).

Empresas privadas e órgãos de pesquisa como, por exemplo, a Embrapa Mandioca e Fruticultura (Cruz das
Almas/BA), através de programas de melhoramento genético, selecionam genótipos de maior tolerância ou resistência aos estresses bióticos e abióticos, inerentes a cultura (GUERRA et al., 2012; BASTOS et al., 2014). Entre as características desejáveis, os programas de melhoramento buscam selecionar genótipos de porta-enxertos cítricos que apresentem: a) resistência a pragas e doenças que afetam as raízes, assim como, sistema radicular capaz de assimilar os nutrientes presentes na solução do solo; $b$ ) adaptabilidade às condições edafoclimáticas do local de implantação; c) compatibilidade com variedades copas comerciais; d) fácil propagação; e) potencial de induzir vigor à copa, além de, bom pegamento e maturação homogênea dos frutos (CASTLE et al., 1993; SOARES et al., 2015). A escolha do porta-enxerto pode influenciar todo o manejo produtivo do pomar, como o porte 
das árvores, a suscetibilidade a doenças, a produtividade e a qualidade dos frutos (CUNHA SOBRINHO et al., 2013).

A citricultura apresenta, historicamente, grande importância social e econômica para o semiárido cearense, como apresentaram Passos et al. (2013) e Sombra et al. (2016), enfrentando como dois de seus principais desafios: a disseminação generalizada da "gomose", doença fungica ocasionada por Phytophthora spp., que na década de 1980 proliferou-se e atingiu pomares cítricos constituídos por laranja doce (Citrus sinensis L. Osbeck) (Rutaceae), altamente susceptível, (PASSOS et al., 2013) e a baixa qualidade da água disponível para fins de irrigação, seja superficial ou subterrânea (SOMBRA et al., 2018a).

A ocorrência de águas salobras ou contaminadas por metais, com teores de bicarbonato ferroso dissolvido que leva a formação da chamada 'capa rosa', é comum em determinadas regiões do estado do Ceará, e quando utilizada na irrigação, geralmente, leva ao acumulo de ferro (Fe), como concreções ferruginosas, nas tubulações e área irrigável (precipitado), tornando as condições adversas ao desenvolvimento radicular e a absorção de nutrientes do solo, podendo ocasionar fitotoxidez direta, devido a absorção excessiva desse elemento pela planta, ou mesmo, indireta, pela inibição de absorção de outros nutrientes, essenciais ao metabolismo vegetal, o que agrava-se diante da escassez de trabalhos na literatura sobre os possíveis estresses sofridos pelas plantas cítricas, e demais culturas agrícolas (MORUZZI; REALI, 2012; PASSOS; RUIZ, 2015).

Diante dos desafios e do potencial de adoção de combinações entre copas de interesse comercial com portaenxertos resistentes a estresses bióticos, como a gomose, ou abióticos, como o excesso de Fe na água e no solo, torna-se necessário o estudo sobre a diversificação no uso de genótipos de citros, viabilizando a citricultura em condições edafoclimáticas de semiárido nordestino.

$\mathrm{O}$ trabalho objetivou avaliar os efeitos do excesso de ferro sobre a emergência e desenvolvimento inicial de genótipos de porta-enxertos cítricos.

\section{MATERIAL E MÉTODOS}

2.1. Caracterização da área de estudo

O experimento foi desenvolvido, entre dezembro de 2016 e março de 2017, em ambiente protegido (Área: $220 \mathrm{~m}^{2}$ ) na Unidade de Ensino, Pesquisa e Extensão (UEPE) do Instituto Federal de Educação, Ciência e Tecnologia do Ceará (IFCE), campus Limoeiro do Norte, localizado a latitude $5^{\circ} 10^{\prime} 56.47^{\prime}$ ' $\mathrm{S}$ e longitude $38^{\circ} 0^{\prime} 46.33^{\prime}$, a uma altitude aproximada de 146m, Limoeiro do Norte, Ceará, Brasil (Figura 1).

A clima da região do Baixo Jaguaribe é classificado como seco e muito quente, do tipo BSw'h' (Köppen) (ALVARES et al., 2013), com duas estações climáticas: uma seca, que vai geralmente de junho a janeiro; e uma chuvosa, de fevereiro a maio (verão e outono). O ambiente protegido é do tipo casa de vegetação, implantado com orientação Leste-Oeste. A cobertura consiste em arcos de ferro galvanizado, revestida por polietileno de baixa densidade (PEBD), transparente, com espessura de $100 \mu \mathrm{m}$, apoiada sobre pilares de madeira e laterais protegidas com tela antiafídica.

\subsection{Obtenção dos genótipos de porta-enxertos de citros}

As sementes foram obtidas pelo Núcleo de Pesquisa em Citros (NPCitrus/Ceará), em parceria com a Embrapa Semiárido (Petrolina/PE), junto ao Banco Ativo de
Germoplasma de Citros (BAG - Citrus) da Embrapa Mandioca e Fruticultura Tropical (Cruz das Almas/BA).

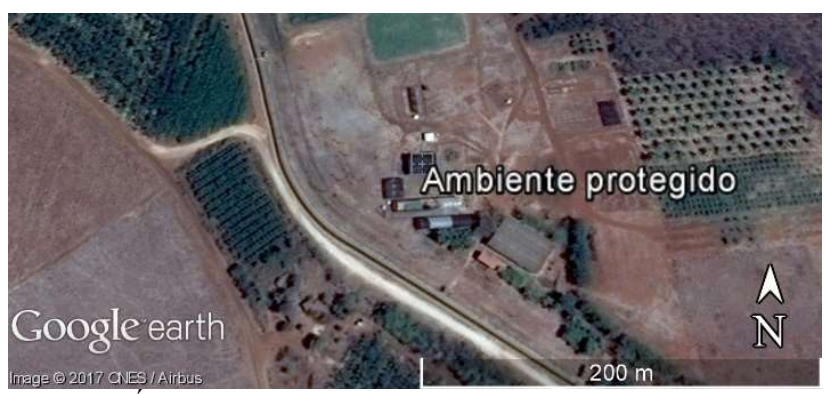

Figura 1. Área de estudo (5॰10'56.47" S; 380'46.43" O), ambiente protegido (casa de vegetação), Campus Limoeiro do Norte (IFCE), Limoeiro do Norte - CE, Brasil. Fonte: Google Earth Pro 7.1.5. Data da imagem: 29/12/2016.

Figure 1. Study area $\left(5^{\circ} 10^{\prime} 56.47^{\prime \prime} \mathrm{S} ; 38^{\circ} 0^{\prime} 46.43^{\prime \prime} \mathrm{O}\right)$, protected environment (greenhouse), Limoeiro do Norte Campus (IFCE), Limoeiro do Norte-CE, Brazil.

\subsection{Obtenção dos substratos e semeadura}

O substrato controle consistiu de composto a base de areia quartsoza, terra de formigueiro e composto orgânico (compostagem), numa proporção de 1:1:1, peneirado e homogeneizado. Já o substrato com ferro $(\mathrm{Fe})$ recebeu a adição de areia com excesso de hidróxido de ferro precipitado, simulando as condições de acúmulo devido a irrigação com água contaminada com teores de $\mathrm{Fe}$, numa proporção de 1:1 (composto: areia rica em Fe). A areia com excesso de Fe foi coletada diretamente no filtro de areia de um sistema de irrigação, numa propriedade rural no município de Russas, que utilizava água com excesso de Fe nas culturas cultivadas.

A semeadura foi realizada em tubetes cônicos de polietileno preto (capacidade aproximada de $180 \mathrm{~cm}^{3}$ ), vazados na parte basal, fixados em bancadas de madeira a 1,2 $\mathrm{m}$ do solo, semeando-se uma semente por tubete, na posição horizontal a uma profundidade de $1,5 \mathrm{~cm}$ a $2 \mathrm{~cm}$ (DE ARAÚJO et al., 2015).

As irrigações foram realizadas por microaspersão, com turno de rega diário e tempo de irrigação médio de uma hora e trinta minutos $\left(5 \mathrm{~mm} \mathrm{dia}^{-1}\right)$.

\subsection{Delineamento experimental}

Adotou-se delineamento em blocos casualizados (DBC), em esquema fatorial $5 \times 2$, avaliando cinco porta-enxertos (fator 1) cultivados em dois substratos (fator 2), com quatro repetições (blocos) e parcela útil de 15 sementes (unidade). Os porta-enxertos avaliados consistiram do limoeiro 'Cravo Santa Cruz'; citrandarins 'Riverside', 'San Diego' e 'Índio', além de, tangerineira 'Sunki Tropical', cultivados com ou sem óxido de Fe no substrato, como fatores secundários.

\subsection{Variáveis analisadas}

Analisaram-se as porcentagens de emergência (PE), do vigésimo ao nonagésimo dia após a semeadura (DAS), com intervalo de 2 dias entre leituras, realizando-se inspeção visual e anotando-se as emergências sempre que a plúmula se encontrava projetada ao menos $2 \mathrm{~mm}$ acima da superfície do substrato, determinando-se a taxa final de emergência (TFE) e taxa final de poliembrionia (TFP), e utilizando-se dos dados obtidos para cálculo do índice de velocidade de emergência (IVE), através da fórmula de Maguire descrita por Nakagawa (1994) e Oliveira et al. (2009), conforme: 


$$
\operatorname{IVE}=\mathrm{E}_{1} / \mathrm{N}_{1}+\mathrm{E}_{2} / \mathrm{N}_{2}+\mathrm{E}_{3} / \mathrm{N}_{3} \ldots+\mathrm{E}_{\mathrm{n}} / \mathrm{N}_{\mathrm{n}} \text {, (Equação 1) }
$$

em que: $E_{1}, E_{2}$ e $E_{n}$ são os números de plântulas emergidas na primeira, segunda leitura, até a contagem anterior; $\mathrm{N}_{1}, \mathrm{~N}_{2}$ e $\mathrm{N}_{\mathrm{n}}$ são os números de dias transcorridos desde a semeadura para a primeira, segunda, até a última leitura.

Realizaram-se avaliações biométricas aos 30, 60 e 90 dias após a semeadura (DAS), registrando-se: a) altura das plântulas $(\mathrm{H})$, medida do colo ao ápice; e diâmetro do caule (D), mensurado ao nível do colo com auxílio de paquímetro digital, selecionando-se amostras aleatórias para determinação da massa fresca (MF) e massa seca (MS), obtida após secagem em estufa de circulação forçada de ar, a $45^{\circ} \mathrm{C}$, até massa constante (AZEVEDO et al., 2015; RODRIGUES et al., 2015)

\subsection{Análise estatística}

Realizou-se análise de regressão $(\mathrm{p} \leq 0,05)$ para a emergência em função do tempo, calculando-se a equação de regressão $(y)$ e o coeficiente de determinação $\left(\mathrm{R}^{2}\right)$ para cada tratamento.

Os dados obtidos foram submetidos à análise de variância (ANOVA), comparando-se as médias pelo teste de Tukey ( $\mathrm{p} \leq$ 0,05), com auxílio do software estatístico ASSISTAT ${ }^{\circledR} 7.7$.

\section{RESULTADOS}

Registrou-se correlação linear positiva $\left(R^{2}>80 \%\right)$ entre a emergência e o tempo para todos os tratamentos, indicando que o tempo, influi direta e positivamente sobre o número de plântulas emergidas, independente do excesso de ferro $(\mathrm{Fe})$ no substrato, sendo que os citrandarins 'Riverside' e 'Indio' obtiveram os coeficientes de determinação mais elevados quando submetidos ao estresse por excesso de Fe no substrato, apresentando dados com maior uniformidade e alinhados com a curva de emergência nos 90 dias de avaliação (Tabela 1).

$\mathrm{O}$ excesso de $\mathrm{Fe}$ no substrato inferiu efeitos adversos a emergência do citrandarin 'Riverside', que sofreu diminuição no número de plântulas emergidas após as primeiras leituras, como constata-se na Tabela 2. Aos 30 dias após a semeadura, o substrato controle proporcionou emergência de 84,92\%, enquanto, constatou-se que o substrato com excesso de $\mathrm{Fe}$ inferiu apenas 63,27\% de plântulas emergidas (Tabela 2).

Tabela 1. Equações de regressão e coeficiente de determinação $\left(\mathrm{R}^{2}\right)$ das plântulas de porta-enxertos cítricos nos substratos sem e com excesso de ferro, Limoeiro do Norte - CE, Brasil.

Table 1. Regression equations and coefficient of determination (R2) of citrus rootstock seedlings on substrates without and with excess iron, Limoeiro do Norte - CE, Brazil.

\begin{tabular}{|c|c|c|c|}
\hline \multicolumn{4}{|c|}{ Análise de regressão } \\
\hline Genótipo & Subst. & Equação & $\mathrm{R}^{2}(\%)$ \\
\hline \multirow{2}{*}{ LCSC } & Controle & $y=-0,124 x^{2}+8,036 x-24.736$ & 89,08 \\
\hline & +Ferro & $y=-0,117 x^{2}+7,792 x-27.527$ & 91,42 \\
\hline \multirow{2}{*}{ CRD } & Controle & $y=-0,113 x^{2}+7,454 x-23.112$ & 91,20 \\
\hline & +Ferro & $y=-0,084 x^{2}+5,765 x-18.475$ & 93,69 \\
\hline \multirow{2}{*}{ CSD } & Controle & $y=-0,114 x^{2}+7,247 x-18.186$ & 87,21 \\
\hline & +Ferro & $y=-0,110 x^{2}+7,047 x-16.267$ & 86,54 \\
\hline \multirow{2}{*}{ CID } & Controle & $y=-0,121 x^{2}+7,845 x-22.661$ & 89,62 \\
\hline & + Ferro & $y=-0,120 x^{2}+7,933 x-27.360$ & 92,88 \\
\hline \multirow{2}{*}{ TST } & Controle & $y=-0,097 x^{2}+6,294 x-14.671$ & 85,15 \\
\hline & + Ferro & $y=-0,111 x^{2}+7,188 x-20,755$ & 90,34 \\
\hline
\end{tabular}

$\mathrm{LCSC}=$ Limoeiro 'Cravo Santa Cruz'; $\mathrm{CRD}=$ Citrandarin 'Riverside'; $\mathrm{CSD}=$ Citrandarin 'San Diego'; $\mathrm{CID}=$ Citrandarin 'Indio'; TST= Tangerineira 'Sunki Tropical'.

Nativa, Sinop, v. 7, n. 1, p. 50-58, jan./fev. 2019
Tabela 2. Emergência (E) das plântulas de porta-enxertos cítricos aos 30, 60 e 90 dias após a semeadura nos substratos sem e com excesso de ferro, Limoeiro do Norte - CE, Brasil.

Table 2. Emergence (E) of citrus rootstock seedlings at 30,60 and 90 days after sowing on substrates without and with excess iron, Limoeiro do Norte - CE, Brazil.

\begin{tabular}{|c|c|c|c|c|}
\hline \multicolumn{5}{|c|}{ Taxa de emergência (\%) } \\
\hline \multirow{2}{*}{ Genótipos } & \multirow{2}{*}{$\begin{array}{l}\text { DAS } \\
\text { (dias) }\end{array}$} & \multicolumn{2}{|c|}{ Substrato } & \multirow{2}{*}{$\begin{array}{l}\text { Ponto } \\
\text { médio }\end{array}$} \\
\hline & & Controle & + Ferro & \\
\hline & 30 & $93,29 \mathrm{aA}$ & $91,60 \mathrm{aA}$ & $92,44 \mathrm{a}$ \\
\hline \multirow[t]{2}{*}{ LCSC } & 60 & $94,95 \mathrm{aA}$ & $94,95 \mathrm{aA}$ & $94,95 \mathrm{a}$ \\
\hline & 90 & $94,91 \mathrm{aA}$ & $93,24 \mathrm{aA}$ & $94,07 \mathrm{a}$ \\
\hline \multicolumn{2}{|c|}{ Ponto médio (\%) } & $94,38 \mathrm{~A}$ & $93,26 \mathrm{~A}$ & \\
\hline \multirow{3}{*}{ CRD } & 30 & $84,92 \mathrm{aA}$ & $63,27 \mathrm{cB}$ & $74,09 \mathrm{~b}$ \\
\hline & 60 & $93,24 \mathrm{aA}$ & $79,94 \mathrm{bB}$ & $86,59 \mathrm{~b}$ \\
\hline & 90 & $93,24 \mathrm{aA}$ & $74,93 \mathrm{bB}$ & $84,08 \mathrm{~b}$ \\
\hline \multicolumn{2}{|c|}{ Ponto médio (\%) } & $90,46 \mathrm{~A}$ & $72,71 \mathrm{~B}$ & \\
\hline \multirow{3}{*}{ CSD } & 30 & $88,25 \mathrm{aA}$ & 84,92 bA & $86,58 \mathrm{~b}$ \\
\hline & 60 & $88,25 \mathrm{aA}$ & $88,25 \mathrm{aA}$ & $88,25 \mathrm{a}$ \\
\hline & 90 & $88,25 \mathrm{aA}$ & $88,25 \mathrm{aA}$ & $88,25 \mathrm{a}$ \\
\hline \multicolumn{2}{|c|}{ Ponto médio (\%) } & $88,25 \mathrm{~A}$ & $87,14 \mathrm{~A}$ & \\
\hline \multirow{3}{*}{ CID } & 30 & $93,29 \mathrm{aA}$ & $93,26 \mathrm{aA}$ & $93,27 \mathrm{a}$ \\
\hline & 60 & $94,95 \mathrm{aA}$ & $96,62 \mathrm{aA}$ & $95,78 \mathrm{a}$ \\
\hline & 90 & $94,91 \mathrm{aA}$ & $94,91 \mathrm{aA}$ & $94,90 \mathrm{a}$ \\
\hline \multicolumn{2}{|c|}{ Ponto médio (\%) } & $94,38 \mathrm{~A}$ & $94,93 \mathrm{~A}$ & \\
\hline \multirow{4}{*}{ TST } & 30 & $74,93 \mathrm{bA}$ & $78,26 \mathrm{bA}$ & $76,59 \mathrm{~b}$ \\
\hline & 60 & $79,92 \mathrm{bA}$ & $88,25 \mathrm{aA}$ & $84,08 \mathrm{~b}$ \\
\hline & 90 & $74,93 \mathrm{bA}$ & $84,92 \mathrm{bA}$ & $79,92 \mathrm{~b}$ \\
\hline & Ponto médio (\%) & $76,59 \mathrm{~B}$ & $83,81 \mathrm{~A}$ & \\
\hline \multirow{2}{*}{\multicolumn{2}{|c|}{$\begin{array}{l}\text { C. V. (\%) } \\
\text { Valor F }\end{array}$}} & \multicolumn{2}{|c|}{8,44} & \\
\hline & & \multicolumn{2}{|c|}{$4,6263 * *$} & \\
\hline \multicolumn{2}{|l|}{ Valor de $\mathrm{p}$} & \multicolumn{2}{|c|}{0,00026} & \\
\hline
\end{tabular}

$\mathrm{LCSC}=$ Limoeiro 'Cravo Santa Cruz'; CRD= Citrandarin 'Riverside'; $\mathrm{CSD}=$ Citrandarin 'San Diego'; CID= Citrandarin 'Indio'; TST= Tangerineira 'Sunki Tropical'. As médias seguidas pela mesma letra não diferem estatisticamente entre si (Tukey, $\mathrm{p}<0.05$ ). Colunas - letras minúsculas e Linhas - letras maiúsculas. ** significativo ao nível de $1 \%$ de probabilidade.

A possível fitotoxidez do excesso de Fe no substrato sobre o citrandarin 'Riverside' perdurou ao longo dos 90 dias de avaliação, ocasionando uma emergência final menor que $80 \%$, além de, mortalidade em plântulas emergidas durante o último intervalo de avaliação, o que, em condições similares de estresse, pode reduzir o número de plântulas de porta-enxertos, interferindo nas etapas de produção de mudas cítricas, e consequentemente, pode tornar a atividade mais onerosa.

Os demais porta-enxertos, apesar das condições distintas dos dois substratos (controle e com excesso de ferro), não diferiram estatisticamente quanto aos substratos, apresentando emergência vigorosa em ambos, destacando-se os genótipos de limoeiro 'Cravo Santa Cruz' e citrandarin 'Indio' com maiores médias finais dos dois substratos, com 94,07\% e 94,90\%, respectivamente, de plântulas emergidas aos 90 dias após a semeadura.

Analisando a poliembrionia dos genótipos, inicialmente, constata-se que devido ao efeito do Fe sobre a emergência do citrandarin 'Riverside', o porta-enxerto apresentou menor poliembrionia, com média final de $13,32 \%$ de ocorrência, valor ainda menor apenas no substrato com óxido de Fe, de 8,88\% (Tabela 3).

Já o citrandarin 'Indio' apresentou comportamento distinto dos demais porta-enxertos, apresentando poliembrionia estatisticamente inferior quando submetido ao estresse, atingindo quase a metade do resultado obtido no substrato controle, com apenas $36 \%$ de poliembrionia, o que associada 
a emergência de quase $95 \%$, demonstra que o porta-enxerto apresentou tolerância parcial ao excesso de Fe no substrato para as variáveis emergência e poliembrionia. Importantes variáveis na produção de mudas cítricas, influenciando o número final de plantas obtidas por lote, e os tratos culturais necessários ao desbaste das plântulas emergidas devido a expressão da poliembrionia.

Tabela 3. Taxa de poliembrionia (TP) das plântulas de porta-enxertos cítricos cultivados nos substratos sem e com excesso de ferro, Limoeiro do Norte - CE, Brasil.

Table 3. Polyembryony rate (TP) of citrus rootstock seedlings grown on substrates without and with excess iron, Limoeiro do Norte - CE, Brazil.

\begin{tabular}{|c|c|c|c|}
\hline \multicolumn{4}{|c|}{ Taxa de poliembrionia (\%) } \\
\hline \multirow{2}{*}{ Genótipo } & \multicolumn{2}{|c|}{ Substrato } & \multirow{2}{*}{$\begin{array}{l}\text { Ponto } \\
\text { médio }\end{array}$} \\
\hline & Controle & + Ferro & \\
\hline LCSC & $46,66 \mathrm{abA}$ & $31,10 \mathrm{aA}$ & 38,88 a \\
\hline CRD & $17,77 \mathrm{bcA}$ & $8,88 \mathrm{aA}$ & $13,32 \mathrm{c}$ \\
\hline CSD & $33,33 \mathrm{bcA}$ & $37,77 \mathrm{aA}$ & $35,55 \mathrm{ab}$ \\
\hline CID & 71,10 aA & $36,66 \mathrm{aB}$ & 53,88 a \\
\hline TST & $6,66 \mathrm{cA}$ & $22,22 \mathrm{aA}$ & $14,44 \mathrm{bc}$ \\
\hline Ponto médio & $35,10 \mathrm{~A}$ & $27,32 \mathrm{~B}$ & \\
\hline C. V. $(\%)$ & \multicolumn{2}{|c|}{38,89} & \\
\hline Valor F & \multicolumn{2}{|c|}{$3,732 *$} & \\
\hline Valor de $\mathrm{p}$ & \multicolumn{2}{|c|}{0,02222} & \\
\hline \multicolumn{4}{|c|}{$\begin{array}{l}\text { LCSC = Limoeiro ‘Cravo Santa Cruz'; CRD= Citrandarin 'Riverside'; CSD=- }=\text { = } \\
\text { Citrandarin 'San Diego'; CID= Citrandarin 'Indio'; TST= Tangerineira 'Sunk } \\
\text { Tropical'. As médias seguidas pela mesma letra não diferem estatisticament } \\
\text { entre si (Tukey, p<0.05). Colunas - letras minúsculas e Linhas - letra } \\
\text { maiúsculas. * significativo ao nível de } 5 \% \text { de probabilidade. }\end{array}$} \\
\hline
\end{tabular}

$\mathrm{O} \mathrm{Fe}$ no substrato induziu maior poliembrionia na tangerineira 'Sunki Tropical', elevando o valor de $6,66 \%$ no substrato controle, para 22,22\%. Porém, ainda assim, o valor foi inferior aos obtidos pelos demais porta-enxertos em condições similares de avaliação.

Nas avaliações biométricas realizada após emergência das plântulas para acompanhamento do desenvolvimento vegetativo dos porta-enxertos de citros, foram consideradas a altura e o diâmetro do caule, por interferirem diretamente sobre a realização da enxertia em plantas cítricas, e consequentemente, na redução do tempo para obtenção da altura e espessura desejáveis, que pode reduzir custos operacionais no viveiro de mudas.

O citrandarin 'San Diego' apresentou maior desenvolvimento apical, atingindo altura de $13,23 \mathrm{~cm}$ aos 90 dias após a semeadura, porém, o excesso de Fe no substrato induziu menor altura ao porta-enxerto, que sob estresse atingiu apenas $11,41 \mathrm{~cm}$, significativamente inferior aos $15,06 \mathrm{~cm}$ obtidos quando cultivado no substrato controle (Tabela 4).

A altura média final do citrandarin 'Riverside' não diferiu do 'San Diego', sofrendo efeito adverso similar, o que resultou em reduções estatisticamente significativas (Figuras 2 a 6).

Rodrigues et al. (2015), avaliaram a propagação de portaenxertos híbridos de citros, bem como de variedades comerciais em ambiente protegido (casa de vegetação), obtiveram altura inferior para a maior parcela dos genótipos, destacando-se o citrandarin 'Riverside' com 10,25cm aos 124 dias após a semeadura (DAS), sendo portanto, inferior aos $12,29 \mathrm{~cm}$ de altura obtidos aos 90 DAS no presente trabalho. Rodrigues et al. (2015) obtiveram valores de $7,83 \mathrm{~cm}$ para o citrandarin 'San Diego', e 8,75cm para o citrandarin 'Indio', igualmente inferiores aos obtidos para os mesmos genótipos no presente trabalho, que sobre condições de estresse por excesso de Fe no substrato, foram capazes de atingir alturas de $11,41 \mathrm{~cm}$ e $11,89 \mathrm{~cm}$, respectivamente, aos 90 dias após a semeadura. Indicando o potencial dos porta-enxertos avaliados diante de condições típicas de semiárido, tanto em condições 'controle', como condições de estresse por excesso de Fe.

O substrato com Fe inferiu ao citrandarin 'Indio' maior espessura de caule que o substrato controle, com 2,64mm, enquanto o citrandarin 'Riverside' obteve menor desempenho diante do elemento no substrato, com $2,22 \mathrm{~mm}$ de média final (Tabela 5).

Tabela 4. Altura (H) das plântulas de porta-enxertos aos 30, 60 e 90 dias após a semeadura nos substratos sem e com excesso de ferro, Limoeiro do Norte - CE, Brasil.

Table 4. Height $(\mathrm{H})$ of rootstock seedlings at 30, 60 and 90 days after sowing on substrates without and with excess iron, Limoeiro do Norte - CE, Brazil.

\begin{tabular}{|c|c|c|c|c|}
\hline \multicolumn{5}{|c|}{ Altura $(\mathrm{cm})$} \\
\hline \multirow{2}{*}{ Genótipos } & \multirow{2}{*}{$\begin{array}{l}\text { DAS } \\
\text { (dias) }\end{array}$} & \multicolumn{2}{|c|}{ Substrato } & \multirow{2}{*}{$\begin{array}{l}\text { Ponto } \\
\text { médio }\end{array}$} \\
\hline & & Controle & + Ferro & \\
\hline & 30 & $5,20 \mathrm{cB}$ & $7,75 \mathrm{bA}$ & $6,47 \mathrm{c}$ \\
\hline \multirow[t]{2}{*}{ LCSC } & 60 & $6,61 \mathrm{cA}$ & $6,13 \mathrm{cA}$ & $6,37 \mathrm{c}$ \\
\hline & 90 & $9,68 \mathrm{bA}$ & $8,15 \mathrm{bA}$ & $8,91 \mathrm{~b}$ \\
\hline \multicolumn{2}{|c|}{ Ponto médio (\%) } & $7,16 \mathrm{~A}$ & $7,34 \mathrm{~A}$ & \\
\hline \multirow{3}{*}{ CRD } & 30 & $7,75 \mathrm{bA}$ & $8,39 \mathrm{bA}$ & $8,07 \mathrm{~b}$ \\
\hline & 60 & $12,46 \mathrm{aA}$ & $7,95 \mathrm{bB}$ & $10,20 \mathrm{a}$ \\
\hline & 90 & $12,29 \mathrm{aA}$ & $9,70 \mathrm{bB}$ & $10,99 \mathrm{a}$ \\
\hline \multicolumn{2}{|c|}{ Ponto médio (\%) } & $10,83 \mathrm{~A}$ & $8,68 \mathrm{~B}$ & \\
\hline \multirow{3}{*}{ CSD } & 30 & $8,91 \mathrm{bA}$ & $8,08 \mathrm{bA}$ & $8,49 \mathrm{~b}$ \\
\hline & 60 & $10,90 \mathrm{aA}$ & $8,41 \mathrm{bB}$ & $9,65 \mathrm{a}$ \\
\hline & 90 & $15,06 \mathrm{aA}$ & $11,41 \mathrm{aB}$ & $13,23 \mathrm{a}$ \\
\hline \multicolumn{2}{|c|}{ Ponto médio (\%) } & $11,62 \mathrm{~A}$ & $9,30 \mathrm{~B}$ & \\
\hline \multirow{3}{*}{ CID } & 30 & $6,20 \mathrm{cA}$ & $6,27 \mathrm{cA}$ & $6,23 \mathrm{c}$ \\
\hline & 60 & $8,94 \mathrm{bA}$ & $7,78 \mathrm{bA}$ & $8,36 \mathrm{~b}$ \\
\hline & 90 & $11,00 \mathrm{aA}$ & $11,89 \mathrm{aA}$ & $11,44 \mathrm{a}$ \\
\hline \multicolumn{2}{|c|}{ Ponto médio (\%) } & $8,71 \mathrm{~A}$ & $8,64 \mathrm{~A}$ & \\
\hline \multirow{4}{*}{ TST } & 30 & $7,16 \mathrm{bA}$ & $6,55 \mathrm{cA}$ & $6,85 \mathrm{c}$ \\
\hline & 60 & $7,25 \mathrm{bA}$ & $8,13 \mathrm{bA}$ & $7,69 \mathrm{~b}$ \\
\hline & 90 & $11,85 \mathrm{aA}$ & $11,60 \mathrm{aA}$ & $11,72 \mathrm{a}$ \\
\hline & dio $(\%)$ & $8,75 \mathrm{~A}$ & $8,76 \mathrm{~A}$ & \\
\hline \multicolumn{2}{|l|}{ C. V. $(\%)$} & \multicolumn{2}{|c|}{20,28} & \\
\hline \multicolumn{2}{|l|}{ Valor F } & \multicolumn{2}{|c|}{$8,3913 * *$} & \\
\hline \multicolumn{2}{|l|}{ Valor de $\mathrm{p}$} & \multicolumn{2}{|c|}{$<0,0001$} & \\
\hline
\end{tabular}

$\mathrm{LCSC}=$ Limoeiro 'Cravo Santa Cruz'; CRD= Citrandarin 'Riverside'; $\mathrm{CSD}=$ Citrandarin 'San Diego'; CID= Citrandarin 'Indio'; TST= Tangerineira 'Sunki Tropical'. As médias seguidas pela mesma letra não diferem estatisticamente entre si (Tukey, $\mathrm{p}<0.05)$. Colunas - letras minúsculas e Linhas - letras maiúsculas. ** significativo ao nível de $1 \%$ de probabilidade.

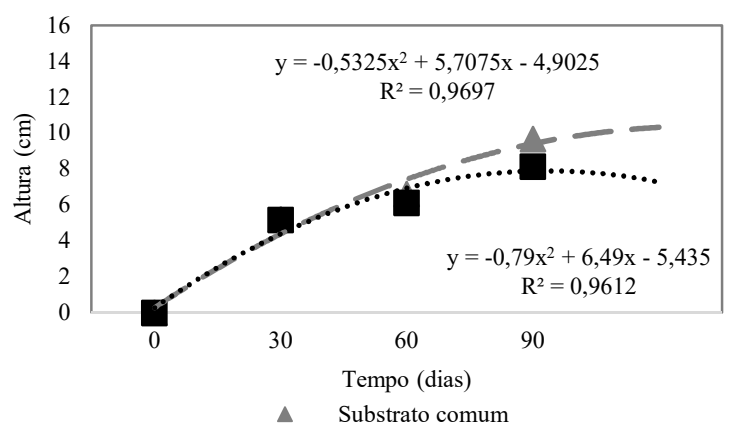

Figura 2. Altura $(\mathrm{H})$ do limoeiro 'Cravo Santa Cruz' nos substratos sem e com excesso de ferro, Limoeiro do Norte - CE, Brasil. Figure 2. Height $(\mathrm{H})$ of 'Santa Cruz' Rangpur lemon on substrates without and with excess of iron, Limoeiro do Norte - CE, Brazil. 


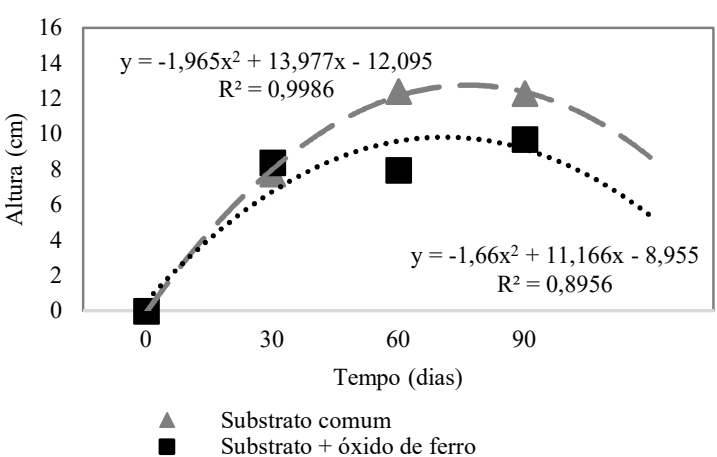

Figura 3. Altura $(\mathrm{H})$ do Citrandarin 'Riverside' nos substratos sem e com excesso de ferro, Limoeiro do Norte - CE, Brasil.

Figure 3. Citrandarin 'Riverside' height $(\mathrm{H})$ on substrates without and with excess iron, Limoeiro do Norte - CE, Brazil.

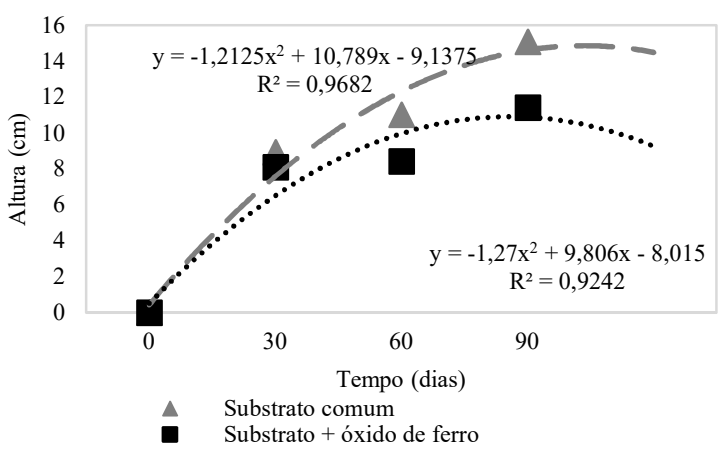

Figura 4. Altura (H) do Citrandarin 'San Diego' nos substratos sem e com excesso de ferro, Limoeiro do Norte - CE, Brasil.

Figure 4. Height $(\mathrm{H})$ of 'San Diego' Citrandarin on substrates without

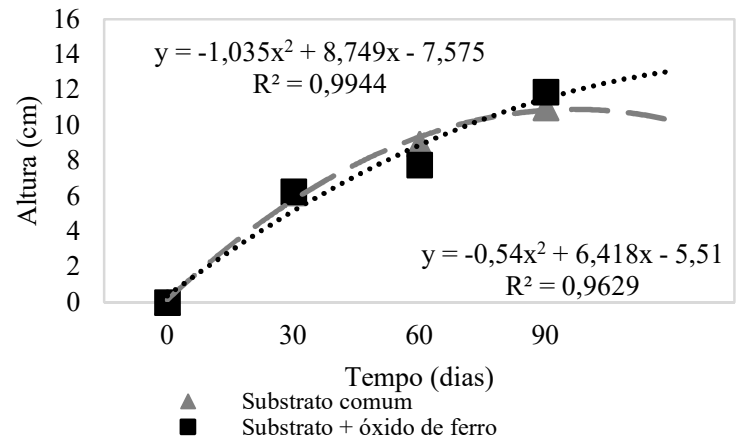

Figura 5. Altura $(\mathrm{H})$ do Citrandarin 'Indio' nos substratos sem e com excesso de ferro, Limoeiro do Norte - CE, Brasil.

Figure 5. Height $(\mathrm{H})$ of 'Indio' citrandarin on substrates without and with excess of iron, Limoeiro do Norte - CE, Brazil.

Para o índice de velocidade de emergência (IVE), os genótipos de limão 'Cravo Santa Cruz', citrandarins 'San Diego' e 'Indio', além da tangerineira 'Sunki Tropical' diferiram estatisticamente do citrandarin 'Riverside', assumindo valores de índice de velocidade de emergência (IVE) superiores a 9,0, demonstrando vigor elevado e uniformidade. Enquanto o citrandarin 'Riverside' registrou os menores valores de IVE, evidenciando possíveis efeitos adversos sofridos pelo excesso de Fe, como por exemplo, a redução do desenvolvimento, que consequentemente, refletiu sobre todas as variáveis avaliadas, e levou aos menores resultados quando houve adição do elemento Fe ao substrato para induzir condições de estresse (Tabela 6).

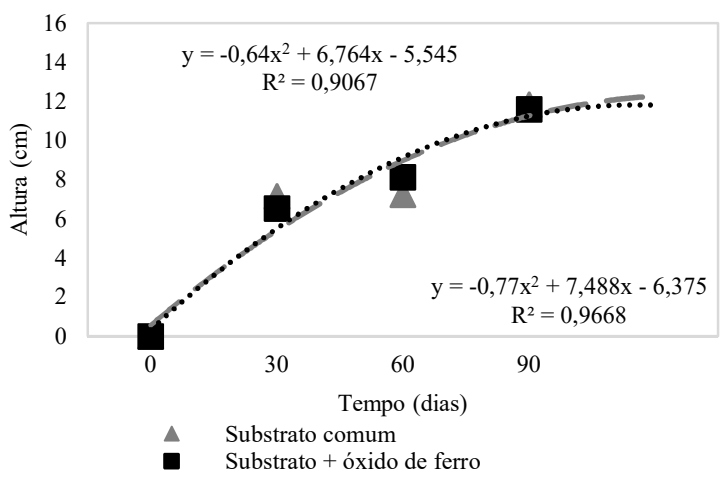

Figura 6. Altura $(\mathrm{H})$ da tangerineira 'Sunki Tropical' nos substratos sem e com excesso de ferro, Limoeiro do Norte - CE, Brasil. Figure 6. Height $(\mathrm{H} / \mathrm{cm})$ of 'Sunki Tropical' tangerine on substrates without and with excess of iron, Limoeiro do Norte - CE, Brazil.

Tabela 5. Diâmetro de caule (D) das plântulas de porta-enxertos cítricos aos 30,60 e 90 dias após a semeadura nos substratos sem e com excesso de ferro, Limoeiro do Norte - CE, Brasil.

Table 5. Stem diameter (D) of citrus rootstocks seedlings at 30, 60 and 90 days after sowing on substrates without and with excess iron, Limoeiro do Norte - CE, Brazil.

\begin{tabular}{|c|c|c|c|c|}
\hline \multicolumn{5}{|c|}{ Diâmetro de caule (mm) } \\
\hline \multirow{2}{*}{ Genótipos } & \multirow{2}{*}{$\begin{array}{c}\text { DAS } \\
\text { (dias) }\end{array}$} & \multicolumn{2}{|c|}{ Substrato } & \multirow{2}{*}{$\begin{array}{l}\text { Ponto } \\
\text { médio }\end{array}$} \\
\hline & & Controle & +Ferro & \\
\hline \multirow{3}{*}{ LCSC } & 30 & $1,53 \mathrm{cB}$ & $1,91 \mathrm{bA}$ & $1,72 \mathrm{~b}$ \\
\hline & 60 & $1,53 \mathrm{cA}$ & $1,45 \mathrm{bA}$ & $1,49 b$ \\
\hline & 90 & $2,07 \mathrm{aA}$ & $1,87 \mathrm{bA}$ & $1,97 \mathrm{a}$ \\
\hline \multicolumn{2}{|c|}{ Ponto médio (\%) } & $1,71 \mathrm{~A}$ & $1,74 \mathrm{~A}$ & \\
\hline \multirow{3}{*}{ CRD } & 30 & $1,91 \mathrm{bA}$ & $1,57 \mathrm{bB}$ & $1,74 \mathrm{~b}$ \\
\hline & 60 & $1,97 \mathrm{bA}$ & $1,56 \mathrm{bB}$ & $1,76 \mathrm{~b}$ \\
\hline & 90 & $2,51 \mathrm{aA}$ & $2,22 \mathrm{aA}$ & $2,36 \mathrm{a}$ \\
\hline \multicolumn{2}{|c|}{ Ponto médio (\%) } & $2,13 \mathrm{~A}$ & $1,78 \mathrm{~B}$ & \\
\hline \multirow{3}{*}{ CSD } & 30 & $1,90 \mathrm{bA}$ & $1,88 \mathrm{bA}$ & $1,89 \mathrm{a}$ \\
\hline & 60 & $2,14 \mathrm{aA}$ & $1,90 \mathrm{bB}$ & $2,02 \mathrm{a}$ \\
\hline & 90 & $3,22 \mathrm{aA}$ & $2,48 \mathrm{aB}$ & $2,85 \mathrm{a}$ \\
\hline \multicolumn{2}{|c|}{ Ponto médio (\%) } & $2,42 \mathrm{~A}$ & $2,08 \mathrm{~B}$ & \\
\hline \multirow{3}{*}{ CID } & 30 & $1,32 \mathrm{cA}$ & $1,57 \mathrm{bA}$ & $1,44 \mathrm{~b}$ \\
\hline & 60 & $1,81 \mathrm{bA}$ & $1,84 \mathrm{bA}$ & $1,82 \mathrm{a}$ \\
\hline & 90 & $2,20 \mathrm{aB}$ & $2,64 \mathrm{aA}$ & $2,42 \mathrm{a}$ \\
\hline \multicolumn{2}{|c|}{ Ponto médio (\%) } & $1,78 \mathrm{~B}$ & $2,01 \mathrm{~A}$ & \\
\hline \multirow{4}{*}{ TST } & 30 & $1,71 \mathrm{bA}$ & $1,53 \mathrm{bA}$ & $1,62 \mathrm{~b}$ \\
\hline & 60 & $1,72 \mathrm{bA}$ & $1,64 \mathrm{bA}$ & $1,68 \mathrm{~b}$ \\
\hline & 90 & $2,27 \mathrm{aA}$ & $2,15 \mathrm{aA}$ & $2,21 \mathrm{a}$ \\
\hline & $\operatorname{dio}(\%)$ & $1,90 \mathrm{~A}$ & $1,77 \mathrm{~A}$ & \\
\hline C. V. (\%) & & \multicolumn{2}{|c|}{18,04} & \\
\hline Valor F & & \multicolumn{2}{|c|}{$6,3049 * *$} & \\
\hline Valor de $\mathrm{p}$ & & \multicolumn{2}{|c|}{$<0,0001$} & \\
\hline
\end{tabular}

$\overline{\mathrm{LCSC}}=$ Limoeiro 'Cravo Santa Cruz'; $\mathrm{CRD}=$ Citrandarin 'Riverside'; $\mathrm{CSD}=$ Citrandarin 'San Diego'; CID= Citrandarin 'Indio'; TST= Tangerineira 'Sunki Tropical'. As médias seguidas pela mesma letra não diferem estatisticamente entre si (Tukey, $\mathrm{p}<0.05$ ). Colunas - letras minúsculas e Linhas - letras maiúsculas. ${ }^{* *}$ significativo ao nível de $1 \%$ de probabilidade.

No trabalho realizado por Rodrigues et al. (2015), os autores obtiveram índices de velocidade de emergência (IVE) inferiores para o limoeiro 'Cravo Santa Cruz', com 8,00; para o citrandarins 'San Diego' e Indio, com 5,47 e 6,48, respectivamente; e para a tangerineira 'Sunki Tropical', com 8,$32 ;$ o que refletiu no desenvolvimento vegetativo dos genótipos, que também apresentaram menor altura.

Rodrigues et al. (2015) obtiveram valores similares para o citrandarin 'Riverside', atingindo 9,41 de índice de velocidade 
de emergência, e aproximando-se dos 9,31 obtidos em condições controle no presente trabalho, que corrobora a influência negativa exercida pelas maiores concentrações de ferro no substrato, sobre o citrandarin 'Riverside', que se mostrou sensível ao acumulo do elemento na rizosfera.

Tabela 6. Índice de velocidade de emergência (IVE) das plântulas de porta-enxertos cítricos nos substratos sem e com excesso de ferro, Limoeiro do Norte - CE, Brasil.

Table 6. Index of emergence velocity (IVE) of citrus rootstock seedlings on substrates without and with excess iron, Limoeiro do Norte - CE, Brazil.

\begin{tabular}{|c|c|c|c|}
\hline \multicolumn{4}{|c|}{ Índice de velocidade de emergência } \\
\hline \multirow{2}{*}{ Genótipos } & \multicolumn{2}{|c|}{ Substrato } & \multirow{2}{*}{$\begin{array}{l}\text { Ponto } \\
\text { médio }\end{array}$} \\
\hline & Controle & + Ferro & \\
\hline LCSC & $9.839 \mathrm{aA}$ & $9.054 \mathrm{aA}$ & $9,44 \mathrm{a}$ \\
\hline CRD & $9.316 \mathrm{bA}$ & $7.165 \mathrm{bB}$ & $8,24 \mathrm{~b}$ \\
\hline CSD & $9.882 \mathrm{aA}$ & $9.834 \mathrm{aA}$ & $9,85 \mathrm{a}$ \\
\hline CID & $10.264 \mathrm{aA}$ & $9.356 \mathrm{aB}$ & $9,81 \mathrm{a}$ \\
\hline TST & $8.986 \mathrm{bA}$ & $9.520 \mathrm{aA}$ & $9,25 \mathrm{a}$ \\
\hline Ponto médio & $9,65 \mathrm{~A}$ & $8,98 \mathrm{~A}$ & \\
\hline C. V. $(\%)$ & \multicolumn{2}{|c|}{11,15} & \\
\hline Valor F & \multicolumn{2}{|c|}{$2,7188 *$} & \\
\hline Valor de $\mathrm{p}$ & \multicolumn{2}{|c|}{0,0213} & \\
\hline \multicolumn{4}{|c|}{$\begin{array}{l}\text { LCSC = Limoeiro ‘Cravo Santa Cruz'; CRD = Citrandarin 'Riverside'; CSD= } \\
\text { Citrandarin 'San Diego'; CID=Citrandarin 'Indio'; TST= Tangerineira 'Sunki } \\
\text { Tropical'. As médias seguidas pela mesma letra não diferem estatisticamente } \\
\text { entre si (Tukey, p }<0.05 \text { ). Colunas - letras minúsculas e Linhas - letras } \\
\text { maiúsculas. * significativo ao nível de } 5 \% \text { de probabilidade. }\end{array}$} \\
\hline
\end{tabular}

O citrandarin 'San Diego' passou a destacar-se dos demais genótipos de porta-enxertos quando considerou-se os teores de massa fresca e seca (MF e MS), representando o acumulo de biomassa como resultado do metabolismo vegetal, característica influenciada diretamente pelo excesso de ferro, como constatou-se através do desempenho dos tratamentos, que exceto citrandarin 'San Diego', que mostrou-se tolerante ao estresse e não distinguiu as condições para desenvolver-se em substrato controle ou com acumulo do elemento Fe no substrato. Os demais genótipos desenvolveram-se menos com a condição de estresse, acumulando menor quantidade de massa fresca (MF) (Tabelas 7 e 8), e portanto, obtendo resultados inferiores de massa seca (MS) (Tabelas 9 e 10).

Ao considerar que o citrandarin 'San Diego' é um portaenxerto híbrido, originado a partir do cruzamento entre tangerineira 'Sunki' (Citrus sunki (Hayata) hort. ex Tanaka) e Poncirus trifoliata (Poncirus trifoliata (L.) Raf.) (Rutaceae), obtido na Estação Experimental de Indio (Califórnia/USA) e introduzido no Brasil pela Embrapa Mandioca e Fruticultura, que tem demonstrado potencial de desenvolver-se satisfatoriamente em condições de estresse abióticos, como por exemplo, solos de baixa fertilidade natural, compactados ou com alta proporção de argila expansiva, além de, resistência a seca e temperaturas elevadas, como demonstram estudos de Bastos et al. (2017a e b), Sombra et al. (2017 e 2018b) ou Loureiro et al. (2016), torna-se necessário fomentar e avaliar o desempenho do genótipo em diferentes regiões citrícolas, buscando evidenciar se há potencial para adoção e diversificação na citricultura nordestina, e possivelmente, na agricultura familiar de regiões com histórico ligado a citricultura como, por exemplo, o Baixo Jaguaribe, no semiárido do Ceará (SOMBRA et al., 2016; SOMBRA et al., 2018a).

$\mathrm{O}$ excesso de $\mathrm{Fe}$ no substrato influenciou diretamente o acumulo de massa seca (MS) na maioria dos tratamentos, reduzindo principalmente os resultados obtidos pelo limoeiro 'Cravo Santa Cruz', que diferiu estatisticamente dos demais, atingindo apenas 4,12g de massa seca total (MS), conforme soma das massas seca da parte aérea e da raiz (Tabelas 9 e 10).

Tabela 7. Massa fresca da parte aérea (MF) das plântulas de portaenxertos cítricos nos substratos sem e com excesso de ferro, Limoeiro do Norte - CE, Brasil.

Table 7. Fresh aerial mass (FM) of citrus rootstocks seedlings on substrates without and with excess iron, Limoeiro do Norte - CE, Brazil.

\begin{tabular}{|c|c|c|c|}
\hline \multicolumn{4}{|c|}{ Massa fresca da parte aérea $(\mathrm{g})$} \\
\hline \multirow{2}{*}{ Genótipos } & \multicolumn{2}{|c|}{ Substrato } & \multirow{2}{*}{$\begin{array}{l}\text { Ponto } \\
\text { médio }\end{array}$} \\
\hline & Controle & +Ferro & \\
\hline LCSC & $10,81 \mathrm{bA}$ & $7,70 \mathrm{~dB}$ & $9,25 \mathrm{~d}$ \\
\hline CRD & $10,66 \mathrm{bA}$ & $8,68 \mathrm{cB}$ & $9,67 \mathrm{~d}$ \\
\hline CSD & $13,30 \mathrm{aA}$ & $12,90 \mathrm{aA}$ & $13,10 \mathrm{a}$ \\
\hline CID & $13,29 \mathrm{aA}$ & $10,61 \mathrm{bB}$ & $11,95 \mathrm{~b}$ \\
\hline TST & $11,35 \mathrm{bA}$ & $8,89 \mathrm{cB}$ & $10,12 \mathrm{c}$ \\
\hline Ponto médio & $11,48 \mathrm{~A}$ & $10,16 \mathrm{~B}$ & \\
\hline C. V. $(\%)$ & \multicolumn{2}{|c|}{2,35} & \\
\hline Valor F & \multicolumn{2}{|c|}{$95,379 * *$} & \\
\hline
\end{tabular}

LCSC= Limoeiro 'Cravo Santa Cruz'; $\mathrm{CRD}=$ Citrandarin 'Riverside'; $\mathrm{CSD}=$ Citrandarin 'San Diego'; CID= Citrandarin 'Indio'; TST= Tangerineira 'Sunki Tropical'. As médias seguidas pela mesma letra não diferem estatisticamente entre si (Tukey, $\mathrm{p}<0.05)$. Colunas - letras minúsculas e Linhas - letras maiúsculas. ** significativo ao nível de $1 \%$ de probabilidade.

Tabela 8. Massa fresca da raiz (MF) dos seedlings de porta-enxertos cítricos nos substratos sem e com excesso de ferro, Limoeiro do Norte $-\mathrm{CE}$, Brasil.

Table 8. Fresh root mass (FM) of seedlings of citrus rootstocks grown on substrates without and with excess iron, Limoeiro do Norte - CE, Brazil.

\begin{tabular}{lrrrr}
\hline \multicolumn{4}{c}{ Massa fresca da raiz $(\mathrm{g})$} \\
\multicolumn{3}{c}{ Substrato } & \multicolumn{2}{c}{$\begin{array}{c}\text { Ponto } \\
\text { médio }\end{array}$} \\
\hline LCSC & Controle & + Ferro & mos \\
CRD & $6,60 \mathrm{cA}$ & $4,93 \mathrm{cB}$ & $5,76 \mathrm{c}$ \\
CSD & $10,76 \mathrm{aA}$ & $7,56 \mathrm{aB}$ & $9,16 \mathrm{a}$ \\
CID & $6,66 \mathrm{cA}$ & $7,03 \mathrm{abA}$ & $6,85 \mathrm{bc}$ \\
TST & $8,46 \mathrm{bA}$ & $6,66 \mathrm{abB}$ & $7,56 \mathrm{~b}$ \\
\hline Ponto médio & $6,93 \mathrm{bcA}$ & $5,43 \mathrm{bcB}$ & $6,18 \mathrm{c}$ \\
C. V. (\%) & $7,88 \mathrm{~A}$ & $6,32 \mathrm{~B}$ & & \\
Valor F & \multicolumn{5}{c}{9,33} \\
\hline
\end{tabular}

$\mathrm{LCSC}=$ Limoeiro 'Cravo Santa Cruz'; CRD= Citrandarin 'Riverside'; CSD= Citrandarin 'San Diego'; CID= Citrandarin 'Indio'; TST= Tangerineira 'Sunki Tropical'. As médias seguidas pela mesma letra não diferem estatisticamente entre si (Tukey, $\mathrm{p}<0.05)$. Colunas - letras minúsculas e Linhas - letras maiúsculas. ** significativo ao nível de $1 \%$ de probabilidade.

O citrandarin 'San Diego' apresentou maior tolerância ao estresse, não se constatando diferença significativa na maior parcela das variáveis do desenvolvimento vegetativo, indicando que sua adoção em condições parciais de acumulo de Fe no solo, através da água de irrigação, pode proporcionar resultados satisfatórios similares ao controle, porém, estudos sobre a exposição do porta-enxerto a longos períodos com excesso de Fe na rizosfera podem corroborar os resultados obtidos.

O citrandarin 'Riverside' foi o genótipo mais sensível (susceptível) ao estresse, não expressando seu potencial máximo, e apresentando resultados inferiores na maior parcela das variáveis em relação ao controle, constatando-se subdesenvolvimento, e até mortalidade de plântulas já emergidas por fitotoxidez. 
Tabela 9. Massa seca da parte aérea (MS) das plântulas de portaenxertos cítricos cultivados nos substratos sem e com excesso de ferro, Limoeiro do Norte - CE, Brasil.

Table 9. Aerial shoot dry mass (DM) of the seedlings of citrus rootstocks grown on substrates without and with excess iron, Limoeiro do Norte - CE, Brazil.

\begin{tabular}{|c|c|c|c|}
\hline \multicolumn{4}{|c|}{ Massa seca da parte aérea $(\mathrm{g})$} \\
\hline \multirow{2}{*}{ Genótipos } & \multicolumn{2}{|c|}{ Substrato } & \multirow{2}{*}{$\begin{array}{l}\text { Ponto } \\
\text { médio }\end{array}$} \\
\hline & Controle & + Ferro & \\
\hline LCSC & $3,36 \mathrm{cA}$ & $2,52 \mathrm{cB}$ & $2,94 \mathrm{~d}$ \\
\hline CRD & $3,76 \mathrm{bA}$ & $2,87 \mathrm{cB}$ & $3,32 \mathrm{c}$ \\
\hline CSD & $4,81 \mathrm{aA}$ & $4,63 \mathrm{aA}$ & $4,72 \mathrm{a}$ \\
\hline CID & $4,27 \mathrm{bA}$ & $3,10 \mathrm{bB}$ & $3,68 \mathrm{~b}$ \\
\hline TST & $3,38 \mathrm{bA}$ & $3,31 \mathrm{bA}$ & $3,35 \mathrm{c}$ \\
\hline Ponto médio & $3,74 \mathrm{~A}$ & $3,47 \mathrm{~B}$ & \\
\hline C. V. $(\%)$ & \multicolumn{2}{|c|}{4,27} & \\
\hline Valor F & \multicolumn{2}{|c|}{$39,846^{* *}$} & \\
\hline
\end{tabular}

$\mathrm{LCSC}=$ Limoeiro 'Cravo Santa Cruz'; $\mathrm{CRD}=$ Citrandarin 'Riverside'; $\mathrm{CSD}=$ Citrandarin 'San Diego'; CID= Citrandarin 'Indio'; TST= Tangerineira 'Sunki Tropical'. As médias seguidas pela mesma letra não diferem estatisticamente entre si (Tukey, $\mathrm{p}<0.05)$. Colunas - letras minúsculas e Linhas - letras maiúsculas. ** significativo ao nível de $1 \%$ de probabilidade.

Tabela 10. Massa seca da raiz (MS) das plântulas de porta-enxertos cítricos cultivados nos substratos sem e com excesso de ferro, Limoeiro do Norte - CE, Brasil.

Table 10. Root dry mass (DM) of citrus rootstock seedlings grown on substrates without and with excess iron, Limoeiro do Norte - CE, Brazil.

\begin{tabular}{|c|c|c|c|}
\hline \multicolumn{4}{|c|}{ Massa seca da raiz (g) } \\
\hline \multirow{2}{*}{ Genótipos } & \multicolumn{2}{|c|}{ Substrato } & \multirow{2}{*}{$\begin{array}{l}\text { Ponto } \\
\text { médio }\end{array}$} \\
\hline & Controle & +Ferro & \\
\hline LCSC & $1,84 \mathrm{cA}$ & $1,60 \mathrm{bA}$ & $1,72 \mathrm{c}$ \\
\hline CRD & $2,50 \mathrm{aA}$ & $1,76 \mathrm{bB}$ & $2,13 \mathrm{~b}$ \\
\hline CSD & 2,63 aA & $2,47 \mathrm{aA}$ & $2,55 \mathrm{a}$ \\
\hline CID & $2,27 \mathrm{abA}$ & $1,62 \mathrm{bB}$ & $1,94 \mathrm{bc}$ \\
\hline TST & $1,99 \mathrm{bcA}$ & $2,21 \mathrm{aA}$ & $2,10 \mathrm{~b}$ \\
\hline Ponto médio & $2,25 \mathrm{~A}$ & $1,93 \mathrm{~B}$ & \\
\hline C. V. $(\%)$ & \multicolumn{2}{|c|}{8,03} & \\
\hline Valor F & \multicolumn{2}{|c|}{$8,305 * *$} & \\
\hline
\end{tabular}

$\mathrm{LCSC}=$ Limoeiro 'Cravo Santa Cruz'; $\mathrm{CRD}=$ Citrandarin 'Riverside'; $\mathrm{CSD}=$ Citrandarin 'San Diego'; CID= Citrandarin 'Indio'; TST= Tangerineira 'Sunki Tropical'. As médias seguidas pela mesma letra não diferem estatisticamente entre si (Tukey, $\mathrm{p}<0.05$ ). Colunas - letras minúsculas e Linhas - letras maiúsculas. ** significativo ao nível de $1 \%$ de probabilidade.

\section{DISCUSSÃO}

O ferro $(\mathrm{Fe})$ é um nutriente essencial para as plantas, porém, sob altas concentrações torna-se nocivo, afetando seriamente o metabolismo e desenvolvimento vegetal, como evidenciaram Passos; Ruiz (2015), destacando que a disponibilidade de Fe na água para fins de irrigação, e seu posterior acúmulo no solo, pode provocar problemas de fitotoxidez em diferentes culturas agrícolas. A fitotoxidez por excesso de Fe relaciona-se, principalmente, com a absorção excessiva do nutriente pela planta em solos argilosos e encharcados, naturalmente ricos em Fe, ou solos com excesso de Fe devido à elevação da concentração pelo uso de água com baixa qualidade para fins de irrigação.

$\mathrm{O}$ ferro $(\mathrm{Fe})$, quando disponível na água utilizada na irrigação das culturas, precipita-se e acumula-se no solo, compreendendo muitas vezes a área irrigável (rizosfera), levando formação de placas de hidróxidos de Fe (concreções), além de inibir a absorção de outros nutrientes pelo sistema radicular, devido as propriedades físicas e químicas do elemento, que lhe conferem o potencial de 'puxar' os demais nutrientes, tornando-os indisponíveis as plantas e causando distúrbios nutricionais sobre a sua fisiologia (GUERRA et al., 2012; PASSOS; RUIZ, 2015; MÜLLER et al., 2017).

Casierra-Posada et al. (2017), avaliaram o efeito do excesso de ferro sobre o crescimento das plantas do sisal (Furcraea hexapetala (Jacq.) Urb.) (Agavaceae) em condições de casa de vegetação, adicionando-se diferentes concentrações de Fe ao substrato, e verificaram que as plantas exibem diferentes graus de tolerância ao excesso de Fe, e que, mesmo as plantas com maior tolerância, tendem a sofrer alterações significativas a medida que se eleva a concentração de Fe no solo, resultando na redução drástica do crescimento das plantas em função da diminuição sistêmica do Índice de conteúdo de Clorofila e da menor alocação de matéria seca, reduzindo-se gradualmente o desenvolvimento vegetativo a à medida que o teor de Fe no substrato aumentou. No estudo desenvolvido por Adamski et al. (2012), avaliando os efeitos de diferentes concentrações de ferro sobre características de crescimento, atividades enzimáticas antioxidantes, absorção de nutrientes e alterações anatômicas na batata-doce (Ipomoea batatas (L.) Lam.) (Convolvulaceae), constataram que o estresse ocasionado pelo excesso de ferro reduz significativamente o desenvolvimento de todas as partes da batata doce, principalmente as raízes, que por sua vez, passam por alterações ultraestruturais em suas células, além de graves danos estruturais às suas mitocôndrias, e a acumulação de ferritina, ou produtos de sua degradação.

Plantas expostas a excessos de ferro, tendem a sofrer um tipo de estresse oxidativo, que leva a formação de radicais hidroxilas que originam intermediários reativos de oxigênio, reduzindo a eficiência fotossintética, necessitando que estudos sejam desenvolvidos para identificar genótipos tolerantes ou resistentes as condições adversas inferidas pelo excesso de ferro, devendo-se quantificar o grau de influência sobre o crescimento vegetal, principalmente em fruteiras, onde o caráter perene da cultura induz planejamento a longo prazo (DE OLIVEIRA JUCOSKI et al., 2013).

Müller et al. (2017), investigaram a tolerância de diferentes cultivares de arroz (Oryza spp.) (Poaceae) ao estresse excesso de $\mathrm{Fe}$, e constataram que as altas concentrações de ferro $(\mathrm{Fe})$ causam um estresse e levam a mudanças substanciais na acumulação de nutrientes nas plantas, limitando bioquimicamente a fotossíntese em arroz, o que varia em função dos diferentes mecanismos de tolerância exibidos pelas cultivares (genótipos), como constatou-se no presente estudo, onde o citrandarin 'San Diego' apresentou maior tolerância que o citrandarin 'Riverside', mesmo considerando que ambos são híbridos pertencentes à mesma família botânica, o que pode ser uma característica agronômica desejável para implantação de pomares em condições parciais, ou regiões, com tendência a exibirem concentrações elevadas de ferro (Fe), e consequentemente, com capacidade de afetar o desenvolvimento vegetal e a produção agrícola.

$\mathrm{Na}$ literatura é possível constatar que o excesso de ferro, além da fitotoxidez devido ao acúmulo junto ao colo da planta, eleva a ineficiência dos sistemas de irrigação, causando entupimentos dos emissores (gotejadores e microaspersores), corrosão das tubulações e conexões, além de reduzir drasticamente a durabilidade do sistema, aumentando ônus gerado ao pequeno e médio citricultor rural, que dispõe apenas da água de baixa qualidade (DE OLIVEIRA JUCOSKI et al., 2013; PASSOS; RUIZ, 2015; SOMBRA et al., 2016). 


\section{CONCLUSÕES}

$\mathrm{O}$ excesso de ferro (Fe) no substrato afetou o desenvolvimento vegetal dos genótipos de porta-enxertos de citros, induzindo subdesenvolvimento e elevando a frequência de mortalidade de plântulas já emergidas, demonstrando que pode ocasionar fitoxicidade se ocorrer nos solos dos pomares cítricos.

O citrandarin 'San Diego' destacou-se com maior altura e caule mais espesso, enquanto o citrandarin 'Riverside' apresentou maior sensibilidade ao estresse, registrando os menores valores de emergência e desenvolvimento.

\section{AGRADECIMENTOS}

Ao Conselho Nacional de Desenvolvimento Científico e Tecnológico $(\mathrm{CNPq})$ pela concessão de bolsas, à Embrapa Mandioca e Fruticultura Tropical e a Embrapa Semiárido, e ao Núcleo de Pesquisa em Citros (NPCitrus/IFCE).

\section{REFERÊNCIAS}

ADAMSKI, J.M.; DANIELOSKI, R.; DEUNER, S.; BRAGA, E. J. B.; Responses to excess iron in sweet potato: impacts on growth, enzyme activities, mineral concentrations, and anatomy. Acta Physiologiae Plantarum, v. 4, n. 3, p. 1827-1836, 2012.2 DOI: https://dx.doi.org/10.1007/s11738-012-0981-3

ALMEIDA, C. O.; PASSOS, O. S. Citricultura brasileira: em busca de novos rumos desafios e oportunidades na região Nordeste. 1. ed. Cruz das Almas: Embrapa Mandioca e Fruticultura Tropical, 2011. 160 p.

ALVARES, C. A.; STAPE, J. L.; SENTELHAS, P. C.; DE MORAES, G.; LEONARDO, J.; SPAROVEK, G. Köppen's climate classification map for Brazil. Meteorologische Zeitschrift, Stuttgart, v.22, n.6, p.711728, 2013. DOI: https://dx.doi.org/10.1127/09412948/2013/0507

AZEVEDO, F. A.; PACHECO, C. D.; SCHINOR, E. H.; DE CARVALHO, S. A.; DA CONCEICAO, P. M. Produtividade de laranjeira Folha Murcha enxertada em limoeiro Cravo sob adensamento de plantio. Bragantia, Campinas, v. 74, n. 2, p. 184-188, 2015. DOI: http://dx.doi.org/10.1590/1678-4499.0374

BASTOS, D. C.; FERREIRA, E. A.; PASSOS, O. S.; SÁ, J. F. DE; ATAÍDE, E. M.; CALGARO, M. Cultivares copa e porta-enxertos para a citricultura brasileira. Informe Agropecuário, Belo Horizonte, v.35, n.281, p.36-45, 2014.

BASTOS, D. C.; SOMBRA, K. E. S.; ANDRADE, H. M.; SANTOS FILHO, L. G.; PASSOS, O. S. Biometric evaluation of Orange cultivar susing different root stocks in the semiarid regi onof Ceará, Brazil. Citrus Research \& Technology, Cordeirópolis, v. 38, n. 1, p. 71-76, 2017 a. DOI: http://dx.doi.org/10.4322/crt.ICC036

BASTOS, D. C.; SOMBRA, K. E. S.; LOUREIRO, F. L. C.; SILVA, A. C. C.; PASSOS, O. S. Initial development of Tahiti acid lime trees on different rootstocks in the semiarid region of Ceará, Brazil. Citrus Research \& Technology, v. 38, n. 1, p. 77-82, 2017b. DOI: http://dx.doi.org/10.4322/crt.ICC045

CASTLE, W. S.; BOWMAN, K. D.; GROSSER, J. W.; FUTCH, S. H.; GRAHAM, J. H. Rootstocks for Florida citrus. Gainesville: Institute of Food and Agricultural Sciences - University of Florida, 1993. 92 p.
CASIERRA-POSADA， F.; CORTES-BAYONA， J. D.; CUTLER, J. Effect of Iron Excess on Growth of Sisal Plants (Furcraea hexapetala). Gesunde Pflanzen, Berlin, v. 69 , n. 3 , p. $123-130,2017$. DOI: http://dx.doi.org/10.1007/s10343-017-0396-6

CUNHA SOBRINHO, A. P.; MAGALHÃES, A. F. J.; SOUZA, A. S.; PASSOS, O. S.; SOARES FILHO, W. S. (Ed.). Cultura dos citros. Brasília, DF: Embrapa, 2013. 1 v. 399 p.

DE ARAÚJO, R. A.; SIQUEIRA, D. L.; MARTINEZ, C. A.; FERNANDES, A. R. Características biométricas, índice SPAD-502 e emissão da fluorescência em porta-enxertos de citros. Revista Ceres, Viçosa, v. 51, n. 294, p. 1-9, 2015.

DE OLIVEIRA JUCOSKI, G.; CAMBRAIA, J.; RIBEIRO, C.; DE OLIVEIRA, J. A. Excesso de ferro sobre o crescimento e a composição mineral em Eugenia uniflora L. Revista Ciência Agronômica, Fortaleza, v. 47, n. 4, p. 720-728, 2016.

GUERRA, D.; SCHIFINO-WITTMAN, M. T.; SCHWARZ, S. F.; DUTRA DE SOUZA, P. V.; WEILER, R. L. Caracterização morfológica, determinação do número de embriões e taxa de poliembrionia em três porta-enxertos híbridos de citros. Bragantia, Campinas, v. 71, n. 2, p. 196-201, 2012. DOI: http://dx.doi.org/10.1590/S000687052012000200007

LOUREIRO, F. L. C.; SOMBRA, K. E. S.; SILVA, A. C. C.; PASSOS, O. S.; BASTOS, D. C. Avaliação Biométrica de Pomeleiro Star Ruby sob Diferentes Porta-Enxertos no Semiárido do Ceará. Revista Técnico Científica do CREA-PR, Curitiba, v. 1, p. 1-9, 2016.

MORUZZI, R. B.; REALI, M. A. P. Oxidação e remoção de ferro e manganês em águas para fins de abastecimento público ou industrial: uma abordagem geral. Revista de Engenharia e Tecnologia, Ponta Grossa, v. 4, n. 1, p. 2943, 2012.

MÜLLER, C.; DA SILVEIRA SILVEIRA, S. F.; DE MENEZES DALOSO, D.; MENDES, G. C.; MERCHANT, A.; KUKI, K. N.; OLIVA, M. A.; ALMEIDA, A. M. Ecophysiological responses to excess iron in low land and upland rice cultivars. Chemosphere, Oxford, v. 189, p. 123-133, 2017. DOI: https://doi.org/10.1016/j.chemosphere.2017.09.033

NAKAGAWA, J. Testes de vigor baseados no crescimento de plântulas. In: VIEIRA, R. D.; CARVALHO, N. M. Testes de vigor em sementes. Jaboticabal: FUNEP, 1994. p. 2124.

OLIVEIRA, A. C. S.; MARTINS, G. N.; SILVA, R. F.; VIEIRA, H. D. Testes de vigor em sementes baseados no desempenho de plântulas. InterScience Place, Campos dos Goytacazes, v. 1, n. 4, p. 1-21, 2009.

PASSOS, O. S.; SOARES FILHO, W. S.; BARBOSA, C. J.; CUNHA SOBRINHO, A. P. Clones de laranjeira 'DE RUSSAS'. Cruz das Almas: Embrapa Mandioca e Fruticultura, 2013. 4 p. (Folder/Folheto/Cartilha).

PASSOS, R. R.; RUIZ, H. A. Seleção de acessos de arroz visando à tolerância ao ferro. Revista Ceres, Viçosa, v. 44, n. 255, p. 444-448, 2015.

RODRIGUES, M. J. S.; LEDO, C. A. S.; GIRARDI, E. A.; ALMEIDA, L. A. H.; SOARES FILHO, W. S. Fruit characterization and propagation of hybrid citrus rootstocks in protected environment. Revista Brasileira 
de Fruticultura, Jaboticabal, v. 37, n. 2, p. 457-470, 2015. DOI: http://dx.doi.org/10.1590/0100-2945-068/14

SOARES, L. A. A.; BRITO, M. E. B.; FERNANDES, P. D.; DE LIMA, G. S.; SOARES FILHO, W. S.; DE OLIVEIRA, E. S. Growth of combinations of scion and citrus rootstocks under water stress in greenhouse. Revista Brasileira de Engenharia Agrícola e Ambiental, Campina Grande, v. 19, n. 3, p. 211-2018. 2015. DOI: http://dx.doi.org/10.1590/18071929/agriambi.v19n3p211-217

SOMBRA, K. E. S.; SILVA, A. C. C.; LOUREIRO, F. L. C.; BASTOS, D. C. Citricultura desenvolvida na agricultura de base familiar do município de Russas, Ceará. Cultura Agronômica, Ilha Solteira, v. 25, n. 3, p. 303-316, 2016.

SOMBRA, K. E. S.; SILVA, A. C. C.; LOUREIRO, F. L. C.; UCHÔA, C. N. A Citricultura como Instrumento de Preservação da Agricultura Familiar no Semiárido
Cearense, Brasil. Revista de Extensão e Estudos Rurais, Viçosa, v. 7, n. 1, p. 353-372, 2018a. DOI: https://doi.org/10.18540/rever712018353-372

SOMBRA, K. E. S.; LOUREIRO, F. L. C.; COSTA, A. C., SILVA; SILVA, M. P.; PASSOS, O. S.; BASTOS, D. C. Avaliação biométrica de tangelo Page e pomelo Flame sobre diferentes porta-enxertos no semiárido do Ceará, Brasil. Citrus Research \& Technology, v. 39, e-1038, 2018b. DOI: http://dx.doi.org/10.4322/crt.16418

SOMBRA, K. E. S.; LOUREIRO, F. L. C.; SILVA, A. C. C.; SOMBRA JÚNIOR, C. A.; PASSOS, O. S.; BASTOS, D. C. Desenvolvimento inicial de Tangerineira-Tangor Piemonte sobre diferentes porta-enxertos no Semiárido. In: ALFARO, A. T. S.; TROJAN, D. G. (Orgs.). Descobertas das ciências agrárias e ambientais 3. Ponta Grossa: Atena Editora, 2017. p. 173-180 